
Not for reproduction, distribution or commercial use.

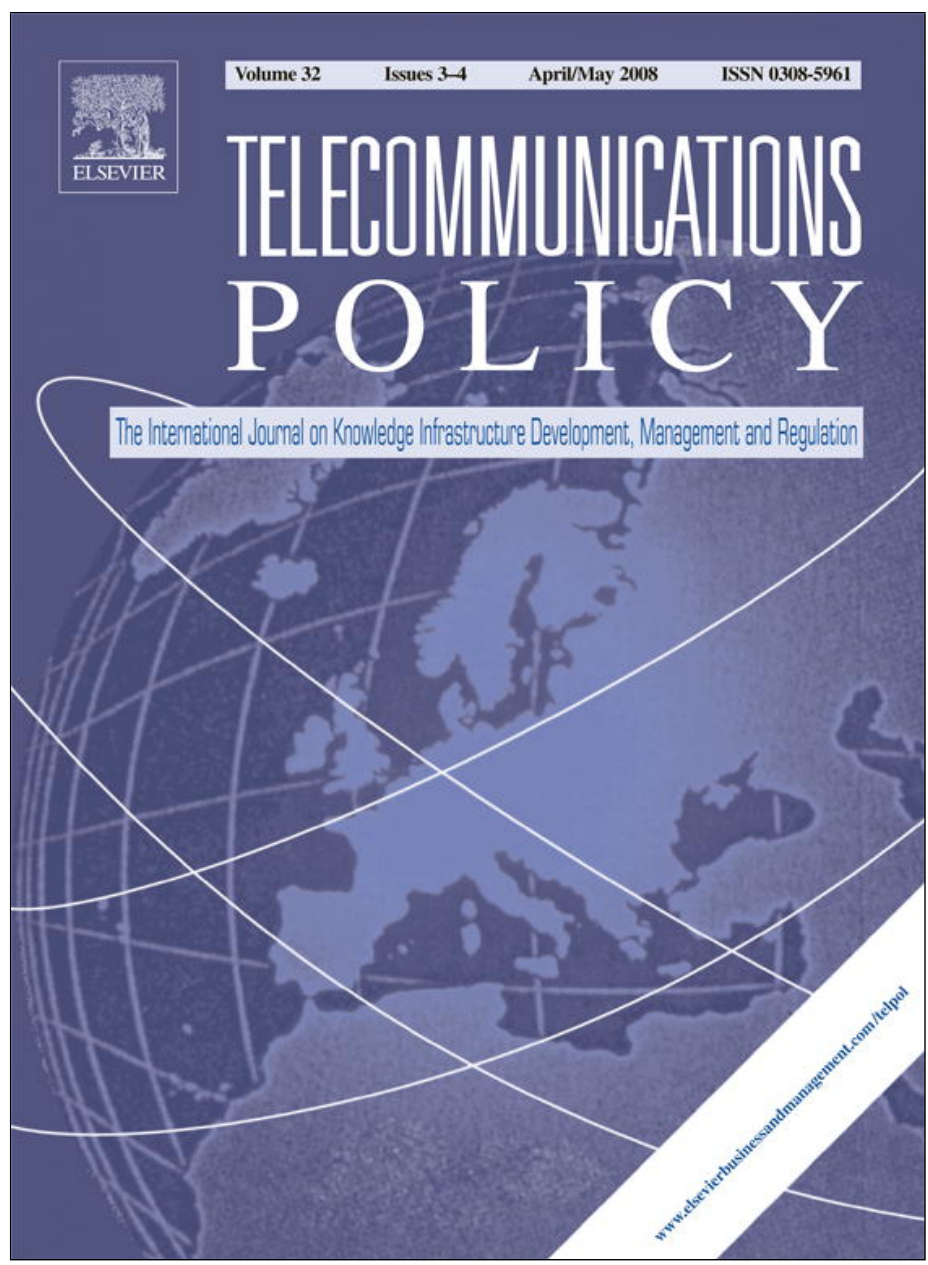

This article appeared in a journal published by Elsevier. The attached copy is furnished to the author for internal non-commercial research and education use, including for instruction at the authors institution and sharing with colleagues.

Other uses, including reproduction and distribution, or selling or licensing copies, or posting to personal, institutional or third party websites are prohibited.

In most cases authors are permitted to post their version of the article (e.g. in Word or Tex form) to their personal website or institutional repository. Authors requiring further information regarding Elsevier's archiving and manuscript policies are encouraged to visit:

http://www.elsevier.com/copyright 


\title{
Diffusion models of mobile telephony in Greece
}

\author{
Christos Michalakelis*, Dimitris Varoutas, Thomas Sphicopoulos \\ Department of Informatics and Telecommunications, University of Athens, Panepistimiopolis, Ilisia, 15784 Athens, Greece
}

\begin{abstract}
This paper examines and presents the diffusion rate of mobile telephony subscriptions in Greece. Following the evaluation of the most widely used aggregate technology diffusion models (such as the Bass model, the Fisher-Pry model, the Gompertz models and some representatives of the logistic variants), it becomes evident that these S-shaped models are suitable enough for accurate fitting and forecasting the diffusion of mobile telephony. The analysis of the diffusion process in Greece provides some interesting aspects of mobile penetration such as the correlation between the diffusion speed and the number of competing operators as well as other socioeconomic and regulatory aspects. As a result of the estimation of $2 \mathrm{G}$ 's diffusion process parameters, the potential market size and the analysis of the techniques for the appropriate model selection, this analysis can be considered as a means of providing an insight into the estimation of the diffusion shapes of the forthcoming generations of mobile telephony and telecommunication products and services in Greece and elsewhere. (C) 2008 Elsevier Ltd. All rights reserved.
\end{abstract}

Keywords: Mobile diffusion; Mobile telecommunications; Bass model; Gompertz model; Fisher-Pry model; Logistic models

\section{Introduction}

As mobile communications have experienced significant development during recent years, a considerable volume of research has been carried out with particular emphasis on their diffusion at national (Botelho \& Pinto, 2004) as well as at international level (Fildes \& Kumar, 2002; Gruber, 2005) Mobile services have faced rapid diffusion in Europe, as a result of technological change and governmental decisions and regulations, as well as competition at national level (Gruber, 2005). The study of the diffusion process of mobile services is of paramount importance in understanding the factors influencing further development of mobile networks towards the introduction of $3 \mathrm{G} / 4 \mathrm{G}$ networks and the derived knowledge should be seriously taken into consideration for building appropriate strategic plans and for constructing the necessary supporting infrastructure.

Diffusion theory is a methodological approach used for estimating the adoption of technological innovations or other products or services. Corresponding models based on diffusion theory are of major importance for the determination of the product's expected life cycle and associated parameters such as maximum penetration. The cumulative diffusion shapes of innovations are often described by sigmoid patterns, the so-called S-shaped growth patterns. The early stages of a diffusion pattern are usually based on a

\footnotetext{
${ }^{*}$ Corresponding author. Tel.: + 302107275318 ; fax: +302107275601 .

E-mail addresses: michalak@di.uoa.gr (C. Michalakelis), arkas@di.uoa.gr (D. Varoutas), thomas@di.uoa.gr (T. Sphicopoulos).
} 
number of early buyers (adopters). These initial adopters of the services are forming the "critical mass", which is of critical importance for the "ignition" of the diffusion process and, consequently, for the saturation level and the time it will be achieved. Innovators' decisions to adopt the service are independent from the decisions of the rest of the population. Apart from the innovators, there is another category of adopters, the imitators, who proceed to the adoption of the service, influenced by interaction with innovators (word-of-mouth) and by external influences such as mass media communication and other communication channels. Finally, the market reaches maturity, when the maximum number of adopters among the considered population is met (market saturation) (Mahajan, Muller, \& Bass, 1990; Mahajan, Muller, \& Srivastava, 1990).

Based on these concepts, the present work attempts to provide an insight concerning estimation and forecasting of the underlying mechanics of mobile telephony. Towards this goal, a number of diffusion models are employed in order to study their ability to capture diffusion process dynamics. The corresponding results provide an overview of the estimations for the referenced market's ultimate potential and can be considered as the lower and upper forecasting boundaries of the ultimate values that the studied diffusion process of mobile telephony in Greece is expected to reach. These aspects constitute the main functional utility of the present work.

\section{Mobile telecommunications sector in Greece-market overview}

The telecommunications market in Greece is regulated by the National Telecommunications and Post Commission (EETT, http://www.eett.gr), which was established in 1994, although it did not become actually operational until 1998. The corresponding Ministry for Transport and Communications (MTC) retains responsibility for drafting legislation.

As far as mobile telecommunications are concerned, it is worth mentioning that Greece is the only European country that did not have any analog cellular network (although it was proposed in the late 1980s) and was the first to award licences through a sealed bid auction procedure (Gruber, 2005). The first two GSM 900 licenses were awarded in August 1992 to Telecom Italia's STET (later TIM and from mid-2007 WIND) Hellas and Panafon (now Vodafone) for a $\$ 160$ million fee each. They both started operating during the following year with an exclusivity period for all mobile telecommunications frequencies, including GSM 1800 services, until 2000.

Greece's incumbent fixed-line operator, OTE, was initially excluded from the bidding and this was unusual for Western Europe, as the incumbent fixed-line monopolist was typically given a GSM licence. OTE was awarded its own license no earlier than 1995 and through the establishment of a subsidiary, CosmOTE, which was launched over a GSM 1800 network in April 1998, in order to operate mobile services. OTE exercises its option for a de facto access to radio frequencies without any other competitive process like an auction or a beauty-contest. CosmOTE was very successful in catching up with the competitors and was the first example in Europe where a third entrant is able to become a market share leader so rapidly.

Following the considerable penetration of mobile services, additional frequencies at $1800 \mathrm{MHz}$ were awarded to Vodafone-Panafon and STET Hellas, during May 2001 and additional frequencies in $900 \mathrm{GHz}$ for CosmOTE. At this time, a $2 \mathrm{G}$ spectrum licence was awarded to a new entrant, Q-Telecom, which introduced its services in 2002. Q-Telecom operated as a mobile network operator (MNO) in Athens, but in the rest of the major cities in Greece, it provided services as a mobile virtual network operator (MVNO) through Vodafone's network, exploiting national roaming legislation.

In April 2004, CosmOTE launched i-mode wireless internet services, based on proprietary technology licensed from Japan's NTT DoCoMo. By the end of 2004, the service had 114,000 subscribers, corresponding to $2.7 \%$ of CosmOTE's subscriber base.

The current state of the Greek telecommunications market reveals that growth of $2 \mathrm{G}$ services was limited during the years (2004-2005) as saturation was almost met. This can be also supported by the fact that new subscriptions during 2004 represented a year-to-year growth of $6.4 \%$, against $13.1 \%$ in 2003 and $14.1 \%$ in 2002. Even though Q-Telecom was the fourth ranked provider, it turned out to be a major player in the market affecting growth positively. It managed to collect more than half of the new subscriptions in the year 2004, recording a growth of $96 \%$ as compared to 2003 . 
Regarding ARPU (average revenue per user) figures, Greek mobile telecommunications providers are favored as compared to other European providers ARPU rates (around 30€/month), which is even more attractive given the lower GDP per capita (estimated at approximately $65 \%$ of the European average) of Greece.

In addition, Greece's mobile operators have benefited by increasing roaming revenues (due to tourist industry growth), which is a significant percentage of their revenue stream as well as of significant SMS usage rates (close to $30 € /$ subscriber).

As far as $3 \mathrm{G}$ services are concerned, the regulator announced that the three existing operators (except for Q-Telecom) would be awarded $3 \mathrm{G}$ licences, for which they bid a combined total of $484 \mathrm{M} €$. All three licensees launched commercial $3 \mathrm{G}$ services before the end of 2004. A fourth license, which did not attract any bids, was planned to be re-auctioned in 2006, however, this has not happened. Thus, there are three $3 \mathrm{G}$ operators, each one holding a single licence for $3 \mathrm{G}$ services provision. Growth of $3 \mathrm{G}$ demand is not expected to take off in the short run, since the majority of the corresponding services are limited because of network constraints. An additional constraint to the rapid growth of $3 \mathrm{G}$ telephony is that most of the services were launched as postpaid packages. As prepaid services currently merit a larger market share in users' preferences than the postpaid equivalents, success in adopting the $3 \mathrm{G}$ technology is strongly related to an intensive marketing effort to persuade the users to migrate to the postpaid $3 \mathrm{G}$ telephony services.

\section{Diffusion models for mobile telecommunications}

The best known diffusion models used for technology diffusion purposes are the Bass model (Bass, 1969), the Fisher-Pry model (Fisher \& Pry, 1971), the logistic family models (Bewley \& Fiebig, 1988), as well as the Gompertz model (Gompertz, 1825; Rai, 1999). All these models provide an S-shaped curve describing technology diffusion among specific populations. These models can provide demand forecasting at the aggregate (population) level, rather than at the individual customer level. The latter approach can be described by "choice-based" models, which mainly focus on estimating and quantifying individuals' probability of adopting the innovation, taking into account customer preferences and technology determinants/ characteristics. The underlining idea of these models is the maximization of customer's perceived utility.

The aggregated S-type diffusion models can be derived from a differential equation such as

$$
\frac{\mathrm{d} Y(t)}{\mathrm{d} t}=\delta \times Y(t) \times[S-Y(t)],
$$

where $Y(t)$ represents the total penetration at time $t, S$ the saturation level of the specific technology (the maximum expected adoption level) and $\delta$ is a so-called coefficient of diffusion, which describes the diffusion speed and correlates the diffusion rate with the actual and maximum penetration. It must be noted that the saturation (maximum) level of penetration is a critical and often questionable parameter, especially in the light of multiple subscriptions.

As can be observed in Eq. (1), diffusion speed is proportionate to (a) the population that has already adopted the service, denoted by $Y(t)$, and (b) the remaining market potential represented by $S-Y(t)$.

The concepts of the diffusion theory introduced in the preceding paragraphs are depicted in Fig. 1, which presents the diffusion process of a typical innovation, together with the categories of adopters throughout the whole process. Apart from the innovators, the remaining categories are grouped together under the wider category of imitators. The horizontal axis of the graph refers to the time variable and the vertical one to the annual (or quarterly, or otherwise defined) penetration, expressed as a function of time. The time when the maximum penetration is recorded is the "inflection point" and it refers to the maximum number of adoptions within a time period. After this time, the rate of adoption declines until the product's life cycle is ended, usually by being substituted by its descendant generation. The graph can be easily transformed to show the cumulative penetration over time, which produces the S-shaped curves previously described. One of the main considerations of diffusion analysis is the selection of a model that best describes the diffusion process and the consequent estimation of the corresponding parameters so as to provide the best possible fit to the dataset considered. If this analysis provides reliable results matching the history of the process, forecasting of subsequent diffusion will probably prove reliable as well. 


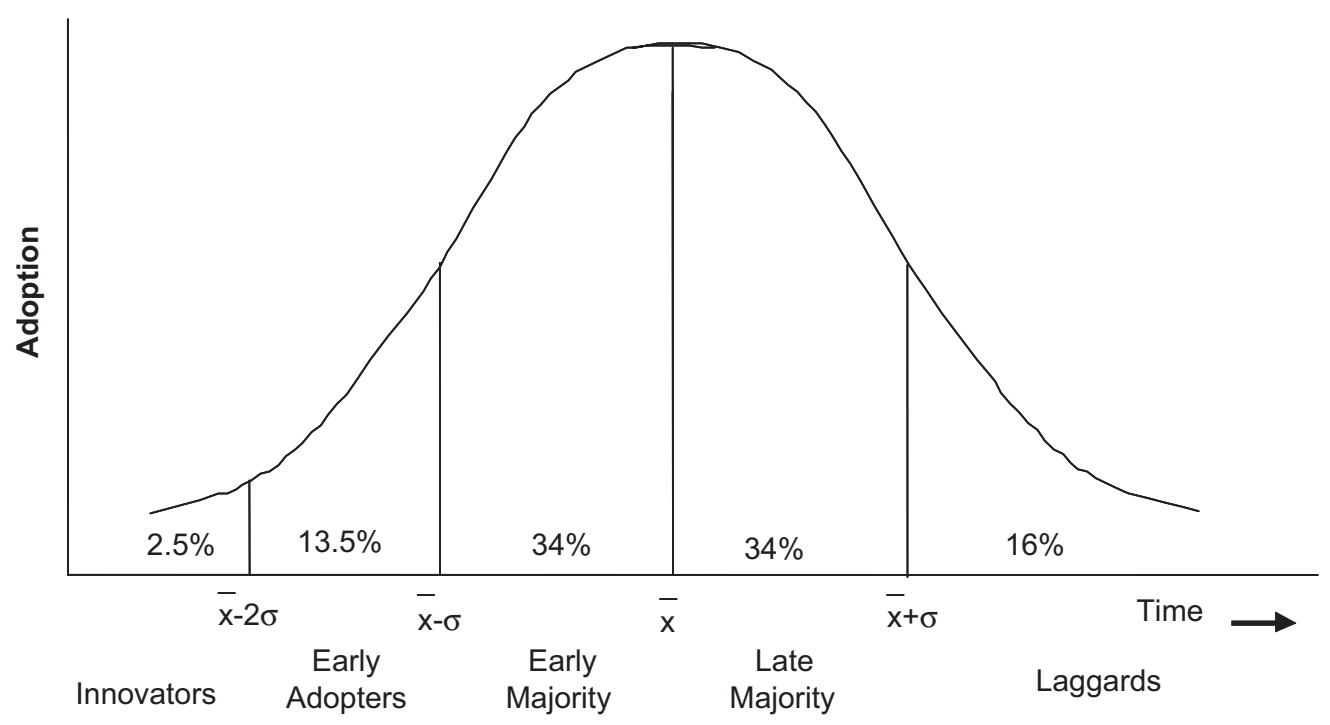

Fig. 1. Idealized diffusion process and life cycle of an innovation and distribution of adopters over time (Source: Mahajan, Muller, and Srivastava (1990)).

Data fitting ability and forecasting performance of some of these models, with respect to $2 \mathrm{G}$ mobile telephony subscriptions in Greece, will be presented in this paper. The results are enriched with an analysis for the selection of a model providing best fit to the particular dataset, a procedure which in turn indicates the most reliable model to be used for forecasting purposes.

The discrete analog of the Bass model (Bass, 1969) is described by the following equation:

$$
A(t)=p \times m+(q-p) \times Y(t-1)-\frac{q}{m}[Y(t-1)]^{2},
$$

and the general form of the model:

$$
A(t)=\frac{m \times(p+q)^{2}}{p} \times \frac{\mathrm{e}^{-(p+q) t}}{\left[(q / p) \mathrm{e}^{-(p+q) t}+1\right]^{2}},
$$

where $m$ is the market potential (maximum possible adoptions envisaged) over the total period of reference. It is used in the same sense as the parameter $S$ (market's saturation level), met in the rest of the diffusion models employed in this work. The difference between $m$ and $S$ is that $m$ refers to the maximum value of adoptions at the peak time, whereas $S$ is the aggregate market potential, related to the cumulative number of adoptions, throughout the studied time period. Market potential $m$, of the Bass model, corresponds to the peak value of instantaneous adoption, as shown in Fig. 1. In this way, diffusion increases, until the market potential is reached and the time that this maximum occurs is the so-called peak time. After this time, adoption decreases until the product's life cycle closes and the product or service ceases to exist in the reference market. Parameter $p$ is the coefficient of innovation corresponding to the probability of an initial purchase at the beginning of the product's life cycle and is related to the size of the initial critical mass of adopters, the innovators. It is of major importance and an influential factor for the rest of the diffusion process. Parameter $q$ is the coefficient of imitation and it refers to the size of the group of the remainder of possible future adopters, the imitators. As defined in the Bass model, the parameters $p$ and $q$ represent the forces of innovative and imitative behavior, assumed to operate in each market, and $p+q$ can have a value different from 1. More specifically, innovators are not influenced in the timing of adoption of the innovation, whereas imitators are influenced by social interaction This interaction is quantified by the $Y(t)$ variable which represents the number of previous adopters or the cumulative adoptions up to time $t$. Finally, $A(t)$ represents sales or, equivalently, adoption during time period $t$. Both formulations (2) and (3) of the Bass model can be easily transformed so as to depict cumulative diffusion, or cumulative penetration being in accordance with the rest of the models' formulations.

Bass has also proposed a generalized version of the model to include decision variables, such as price and advertising (Bass, Krishnan, \& Jain, 1994). Decision variables, in this context, refer to the factors that are of 
major influence over potential adopters towards their decision to adopt the offered service. Application of both the original and the generalized version of the Bass model over a number of datasets from different environments offers evidence of the credibility of the model based on the success in fitting estimated over historical data (Heeler \& Hustad, 1980). However, estimation results were observably improved after using exogenous sources of information to estimate the parameter $m$, as fluctuations in the early stages of the diffusion process could produce inaccurate parameter estimates, thus reducing the model's fitting ability. Performance of the Bass model has also been studied with telecommunication sector data (Wright, Upritchard, \& Lewis, 1997), but other models' fitting ability and comparison of results have not yet been performed.

As far as the Gompertz models are concerned, two variations have been introduced in the literature (labeled as Gompertz I and Gompertz II models, respectively). The Gompertz I model is described by

$$
Y(t)=S \mathrm{e}^{-\mathrm{e}^{-a-b \times t}},
$$

where $b>0$ is a scaling factor, $S$ represents the saturation level and $a$ is the parameter that is related to the point of inflection. $Y(t)$ is the estimated diffusion level at time $t$. The parameters that have to be estimated are $S, a$ and $b$. The exponential part of Eq. (4) can be rewritten as by substituting $\mathrm{e}^{-\alpha}$ with a constant parameter, $A$. In this way, the alternative formulation of the Gompertz model is

$$
Y(t)=S \mathrm{e}^{-A \mathrm{e}^{-b \times t}} \text {. }
$$

The second formulation of the Gompertz model is similar to the first and its parameters are defined similarly. In both formulations, the parameters $\alpha$ and $A$ are related to the time that diffusion reaches $37 \%$ of its upper level $\left(S \mathrm{e}^{-1}\right)$, and parameter $b$ is a measure of the diffusion speed, or how rapidly the adoption progresses.

Concerning the logistic models, their general form is given by

$$
Y(t)=\frac{S}{1+\mathrm{e}^{f(t)}},
$$

where $Y(t)$ is the estimated diffusion level at time $t, S$ denotes the saturation level and $f(t)$ is described by the mathematical formulation:

$$
f(t)=-a-b \times t(m, k) .
$$

The function $t(m, k)$ is a nonlinear function of time in general (apart from the case of the linear logistic model, where $t(m, k)=t)$ and may be described by any one of the following formulations, according to the model's construction.

In the linear instance of the model, the time function is

$$
t(m, k)=t .
$$

This model is also known as the Fisher-Pry model (Fisher \& Pry, 1971).

In the Box-Cox case, the corresponding formulation of $t(m, k)$ is given by

$$
t(m, k)=\frac{(1+t)^{m}-1}{m},
$$

for $k=0$. If $m=1$, then the Box-Cox model coincides with the linear logistic.

Finally, the FLOG (flexible logistic model) formulation is described by

$$
t(m, k)=\frac{\left[(1+k \times t)^{1 / k}\right]^{m}-1}{m} .
$$

The FLOG model is capable of describing the linear logistic and the Box-Cox models, if $m, k$ are given specific values. Thus, for $k=m=1$, the FLOG model becomes the linear logistic, and for $k=1$ and $m>0$, it coincides with the Box-Cox.

The linear logistic model and the Gompertz models are described by functions that are monotonically increasing between the bounds of zero and $S$. The linear logistic model is graphically depicted by a symmetric S-curve and has an inflection point that occurs when $Y(t)=S / 2$. This property means that the maximum growth rate is met when $Y$ reaches half of its saturation level. 
On the other hand, the Gompertz model is asymmetric, with a point of inflection occurring at $Y(t)=S / \mathrm{e}$ which means that it is achieved when $Y$ reaches $37 \%$ of its upper bound.

Because of the fact that the point of inflection is predetermined, either in a symmetric (linear logistic), or an asymmetric (Gompertz) diffusion model, there is a strong need for a model that provides a data - determined rather than constrained point of inflection and degree of symmetry. This requirement was the primary reason for developing a category of flexible logistic models (FLOG models). Two representatives of this category of models, namely the FLOG model and Box-Cox, are used in this paper and their performance with telecommunications data is evaluated.

Another instance of the logistic family models employed for demand estimation is the Tonic model (TONIC, 2000). The model was developed within the IST-TONIC project and provided reasonably accurate fitting over historical data related to high-technology products. IST-TONIC (TechnOecoNomICs of optimized networks and services) is a project that concentrates on the economic evaluation of new communications networks and services in order to identify economically viable solutions for furtherance of the Information Society). The Tonic model can be considered as a generalization of the logistic model and its formulation is

$$
Y(t)=\frac{S}{\left(1+\mathrm{e}^{a+b \times t}\right)^{c}} .
$$

In the TONIC model, if $c=1$ then the derived formulation is the same as in the logistic model. $S$ represents the saturation level of penetration, as in the other models, whereas the rest of the parameters are related to the other characteristics of the curve.

\section{Model evaluation and results}

The dataset used for this analysis comprises the 12 annual total mobile subscriptions in Greece from 1994 until September 2005 (Table 1). Market shares among the four mobile operators in Greece are also included, and numbers include subscriptions from both the prepaid and postpaid sector. The construction of the table was based on data distributed in the officially released results of the companies.

As the reported counts include both active and inactive subscribers, it is worth mentioning that reported subscriptions are defined as the accounts created by operators that do not necessarily correspond to active subscriptions, but to subscriptions for which a bill has been issued during the previous few months.

Regarding Greece's population, the National Statistical Service of Greece (2005) reported a population of approximately 10,964,000 people, in the year 2001, following the national census. In addition, Eurostat's estimation for population growth until the year 2009 reports a mean growth rate of about 21,000 people per

Table 1

Cumulative number of cellular phone subscribers and annual sales in Greece, 1994-2005 (3rd term)

\begin{tabular}{lcccrrrrr}
\hline Year & $\begin{array}{l}\text { Vodafone (ex. } \\
\text { Panafon) }\end{array}$ & CosmOTE & $\begin{array}{l}\text { TIM (ex. } \\
\text { Telestet) }\end{array}$ & Q-Telecom & Total & $\begin{array}{l}\text { Annual } \\
\text { sales }\end{array}$ & Penetration & Rate \\
\hline 1994 & & & & & 167,000 & & 0.02 & \\
1995 & & & & & 273,000 & 106,000 & 0.02 & 0.00 \\
1996 & 320,000 & & 211,000 & & 531,000 & 258,000 & 0.05 & 0.03 \\
1997 & 547,000 & & 391,000 & & 938,000 & 407,000 & 0.09 & 0.04 \\
1998 & $1,069,000$ & 298,838 & 688,614 & & $2,056,452$ & $1,118,452$ & 0.19 \\
1999 & $1,663,000$ & $1,048,352$ & $1,182,751$ & & $3,894,103$ & $1,837,651$ & 0.35 \\
2000 & $2,225,981$ & $2,061,011$ & $1,645,098$ & & $5,932,090$ & $2,037,987$ & 0.54 & 0.10 \\
2001 & $2,884,872$ & $2,943,532$ & $2,135,338$ & & $7,963,742$ & $2,031,652$ & 0.72 & 0.19 \\
2002 & $3,218,707$ & $3,506,338$ & $2,513,642$ & 76,000 & $9,314,687$ & $1,350,945$ & 0.85 \\
2003 & $3,782,737$ & $3,917,010$ & $2,402,777$ & 366,536 & $10,469,060$ & $1,154,373$ & 0.95 & 0.13 \\
2004 & $4,064,000$ & $4,151,000$ & $2,323,866$ & 854,436 & $11,393,302$ & 924,242 & 1.04 & 0.10 \\
2005 (Q3) & $4,302,142$ & $4,509,000$ & $2,257,312$ & 907,886 & $11,976,340$ & 583,038 & 1.09 & 0.09 \\
\hline
\end{tabular}

Source: Annual reports of Greek mobile providers. 


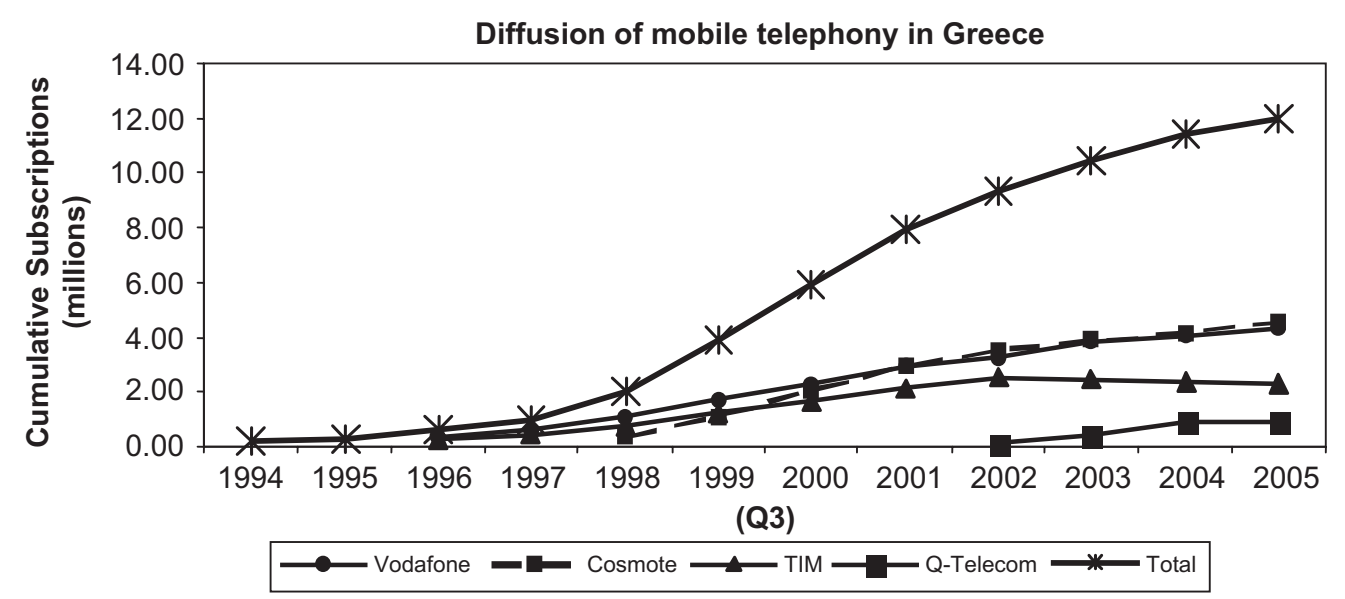

Fig. 2. Diffusion of mobile telephony in Greece, 1994-2005 (Q3) (Source: Annual reports of Greek mobile providers).

year (European Social Statistics, 2001). On the basis of these values, it was assumed that during the period of interest (years 1994-2008), population would face an annual growth of about $0.2 \%$.

As can be depicted from Fig. 2, the mobile subscriptions diffusion process follows an S-curve pattern and the total penetration rate reached its maximum value in the year 2000. After this point, a decrease in the rate of net subscriptions has been recorded. In addition, changes in market shares as result of "churn"-effects and different market strategies can be observed.

\subsection{Methodology for diffusion analysis}

In order to evaluate the diffusion process and the capability of the participating models to capture it with accuracy, the actual penetration data of mobile telephony in Greece was used. This data was split into two parts, "training data" and a "withheld sample". This approach relies on the exclusion of a portion of the real data (withheld sample), corresponding to the last years" observations, and uses the remaining historical data (training data) to estimate the values of the models' parameters, which provide the best estimation results. Hereafter, the "trained" models are evaluated regarding their ability to forecast the excluded data, the withheld sample. In order to increase the robustness of the evaluation of the present work, data concerning 1, 2 and 3 years of data were used as a withheld sample in an equal number of evaluations.

Mean absolute percentage error (MAPE) was selected as a forecast accuracy measure and calculated in each case. MAPE was calculated for all sets of data and the model for which the smallest statistical error was calculated is consequently considered to be the most appropriate to be used for forecasting future diffusion of mobile services. It was also assumed that 2-3 years of forecasting should be sufficient mainly because of the already saturated $2 \mathrm{G}$ market.

It should be also noted that, from an econometric point of view, even if the particular dataset may be considered limited in size, the approach of withholding a portion of the dataset and using it to assess forecasts is quite widely used for determining a model's forecasting ability. This approach is in line with the technology life cycle in general, since innovations and products particularly in the area of high technology usually enjoy life cycles of only a few years' duration, mainly because of the rapid and frequent substitution of a product's generation by its descendant ones.

\subsection{Models evaluation and comparison}

The ability of a model to provide a better fit to data often indirectly depends often on crucial factors, such as the initial "critical mass" of adopters (subscribers), the attributes of the innovation, including the introductory price and the communication channels, which influence the diffusion rate and the potential users' perceived utility gain, following the adoption of the product. As different types of innovations can lead to different growth patterns, different diffusion models are considered more appropriate each time in order to provide 


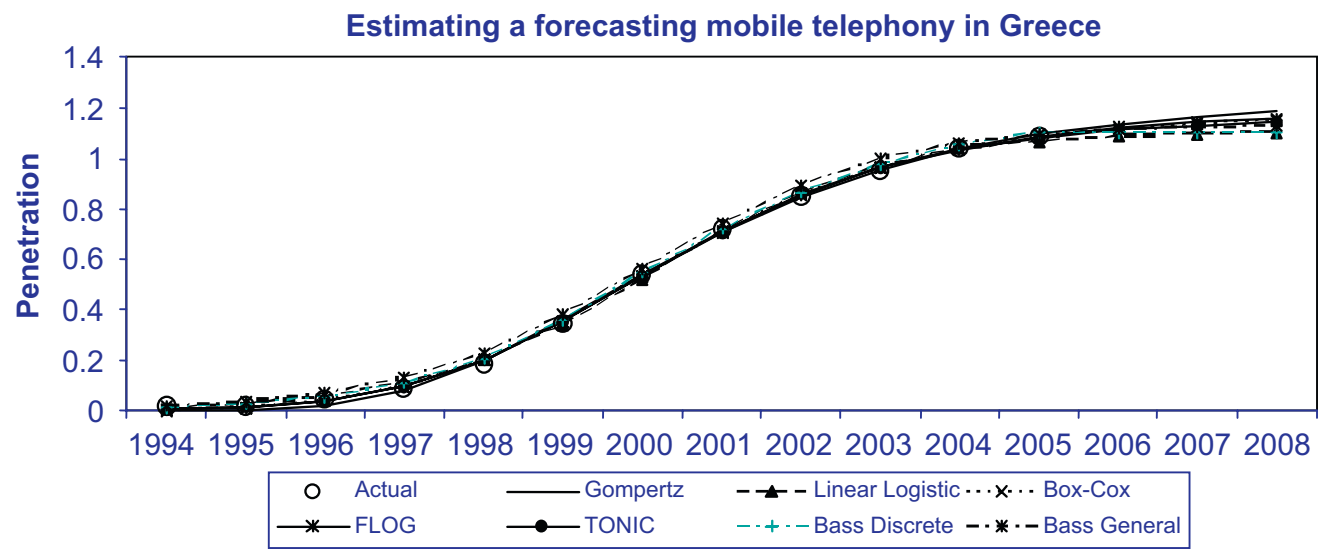

Fig. 3. Cumulative subscriptions estimation of $2 \mathrm{G}$ mobile telephony in Greece. Yearly values to 2005 refer to models' estimation ability based on historical data. Subsequent values are forecasted results derived from each of the participating models.

Table 2

Estimation results and statistical measures of precision (whole dataset)

\begin{tabular}{|c|c|c|c|c|c|c|c|c|}
\hline & $\begin{array}{l}\text { Bass } \\
\text { discrete }\end{array}$ & $\begin{array}{l}\text { Bass } \\
\text { general }\end{array}$ & $\begin{array}{l}\text { Gompertz } \\
\text { I }\end{array}$ & $\begin{array}{l}\text { Gompertz } \\
\text { II }\end{array}$ & $\begin{array}{l}\text { Linear } \\
\text { logistic }\end{array}$ & Box-Cox & FLOG & TONIC \\
\hline Observations number & 12 & 12 & 12 & 12 & 12 & 12 & 12 & 12 \\
\hline$R$-squared & 0.96860 & 0.93354 & 0.99897 & 0.99898 & 0.99880 & 0.99949 & 0.99961 & 0.99954 \\
\hline$R_{\mathrm{a}}$-squared & 0.96075 & 0.91692 & 0.99874 & 0.99874 & 0.99854 & 0.99930 & 0.99938 & 0.99937 \\
\hline S.E. of estimation & 0.01250 & 0.01821 & 0.01497 & 0.01497 & 0.01616 & 0.00118 & 0.01050 & 0.01058 \\
\hline Durbin-Watson statistic & 1.95310 & 1.31113 & 0.75716 & 0.75717 & 1.14351 & 1.15879 & 1.27577 & 1.28122 \\
\hline MSE & 0.00019 & 0.00086 & 0.00017 & 0.00017 & 0.00020 & 0.00008 & 0.00006 & 0.00007 \\
\hline MAE & 0.00782 & 0.01241 & 0.01048 & 0.01048 & 0.01248 & 0.00818 & 0.00714 & 0.00775 \\
\hline MAPE & 11.34587 & 19.00415 & 21.55872 & 21.55872 & 10.43377 & 13.47939 & 11.44783 & 11.41811 \\
\hline $\mathrm{ME}$ & 0.00010 & -0.00030 & 0.00482 & 0.00482 & -0.00178 & 0.00205 & 0.00172 & 0.00163 \\
\hline MPE & 0.21159 & -12.78231 & 19.85078 & 19.85078 & -4.30251 & 11.05834 & 9.30914 & 9.04396 \\
\hline
\end{tabular}

Parameter estimation

$\begin{array}{rllllrlrlrlrrrrrrrr}m & 1.17 & m & 1.12 & S & 1.23 & S & 1.23 & S & 1.11 & S & 1.18 & S & 1.26 & S & 1.16 \\ p & 0.001 & p & 0.0087 & a & -2.575 & a & 13.136 & a & -5.023 & a & -8.105 & a & -6.792 & a & -2.738 \\ q & 0.626 & q & 0.6528 & b & 0.396 & b & 0.396 & b & 0.702 & b & 2.770 & b & 1.296 & b & 0.525 \\ & & & & & & & & & & m & 0.291 & m & -0.043 & c & 2.340 \\ & & & & & & & & & & & & k & -0.134 & & \\ \end{array}$

more accurate estimations and forecasts of the observed process. Moreover, even if the very same innovation is introduced in different geographical areas, it is quite possible that one model will not be able to describe corresponding diffusion processes, and that a different model may be more appropriate to describe diffusion in each case.

The estimation results ${ }^{1}$ for each model over the whole dataset are depicted graphically in Fig. 3, and the corresponding numerical results are presented in Table 2, which reports estimation of the parameters along with the calculated values of the statistical measures. The corresponding discussion involving the results is presented in subsequent sections. The statistics used for the description of the results is the mean absolute percentage error (MAPE) (Table 3).

Another way of demonstrating the models' diffusion estimation ability is presented in Fig. 4, where the errors of estimation are plotted against time. The term "error" is defined in this context as the difference

\footnotetext{
${ }^{1}$ Evaluation of the models performance was based on Datafit v. 7.1 software package (http://www.curvefitting.com). The rest of the analysis was conducted by using Microsoft Excel.
} 
between the observed value and the estimated value for the model considered each time and for the years from 1994 to 2005. The estimation errors of the superior models converge around the horizontal axis, whereas the poorer models provide errors that are spread around the axis.

Regarding the Bass model, its parameters are estimated by nonlinear least squares (NLS) regression, for both the discrete analog and the general formulation of the model. It can be concluded that the Bass model is reliable enough to fit the actual data and therefore to forecast telecommunications penetration. However, observably larger values of statistical errors are recorded, suggesting its nonoptimality for forecasting in comparison with other models. Despite this fact, the construction of the Bass model itself provides the ability to derive some quite useful information for the structure of the referenced market. More precisely, the parameters $p$ and $q$, as these were defined earlier in the description of the Bass model, represent the forces of innovative and imitative behavior that operate in each market. Thus, the obtained values provide an

Table 3

Mean absolute percentage errors (MAPE) for withheld periods (TD: training data, HB: withheld sample, take-off: take-off sample) and for the entire dataset (total)

\begin{tabular}{|c|c|c|c|c|c|c|c|c|}
\hline $\begin{array}{l}\text { Hold back samples } \\
\text { (HB) MAPEs }\end{array}$ & $\begin{array}{l}\text { Bass } \\
\text { discrete }\end{array}$ & $\begin{array}{l}\text { Bass } \\
\text { general }\end{array}$ & $\begin{array}{l}\text { Gompertz } \\
\text { I }\end{array}$ & $\begin{array}{l}\text { Gompertz } \\
\text { II }\end{array}$ & $\begin{array}{l}\text { Linear } \\
\text { logistic }\end{array}$ & Box-Cox & FLOG & TONIC \\
\hline \multicolumn{9}{|l|}{ HB 1 year } \\
\hline TD & 57.16 & 56.96 & 22.96 & 22.96 & 9.48 & 12.87 & 11.44 & 11.09 \\
\hline HS & 28.12 & 1.29 & 1.11 & 1.11 & 3.80 & 1.70 & 1.21 & 1.69 \\
\hline Take-off & 50.16 & 43.84 & 2.37 & 2.37 & 3.82 & 2.22 & 1.92 & 2.06 \\
\hline Total & 54.74 & 52.32 & 21.14 & 21.14 & 9.00 & 11.94 & 10.58 & 10.30 \\
\hline \multicolumn{9}{|l|}{ HB 2 years } \\
\hline $\mathrm{TD}$ & 93.96 & 55.56 & 25.04 & 25.04 & 8.11 & 8.48 & 8.73 & 8.56 \\
\hline HS & 3.57 & 4.14 & 0.92 & 0.92 & 6.35 & 5.51 & 4.88 & 5.11 \\
\hline Take-off & 34.41 & 45.89 & 2.64 & 2.64 & 2.38 & 1.99 & 1.74 & 1.74 \\
\hline Total & 78.90 & 46.99 & 21.02 & 21.02 & 7.81 & 7.98 & 8.09 & 7.98 \\
\hline \multicolumn{9}{|l|}{ HB 3 years } \\
\hline $\mathrm{TD}$ & 50.51 & 53.12 & 25.08 & 25.08 & 8.41 & 8.25 & 8.18 & 8.41 \\
\hline HS & 29.92 & 7.08 & 5.27 & 5.27 & 7.03 & 7.82 & 7.88 & 7.22 \\
\hline Take-off & 47.43 & 47.98 & 2.28 & 2.28 & 1.59 & 1.72 & 1.72 & 1.63 \\
\hline Total & 45.36 & 41.61 & 20.13 & 20.13 & 8.06 & 8.15 & 8.11 & 8.12 \\
\hline
\end{tabular}

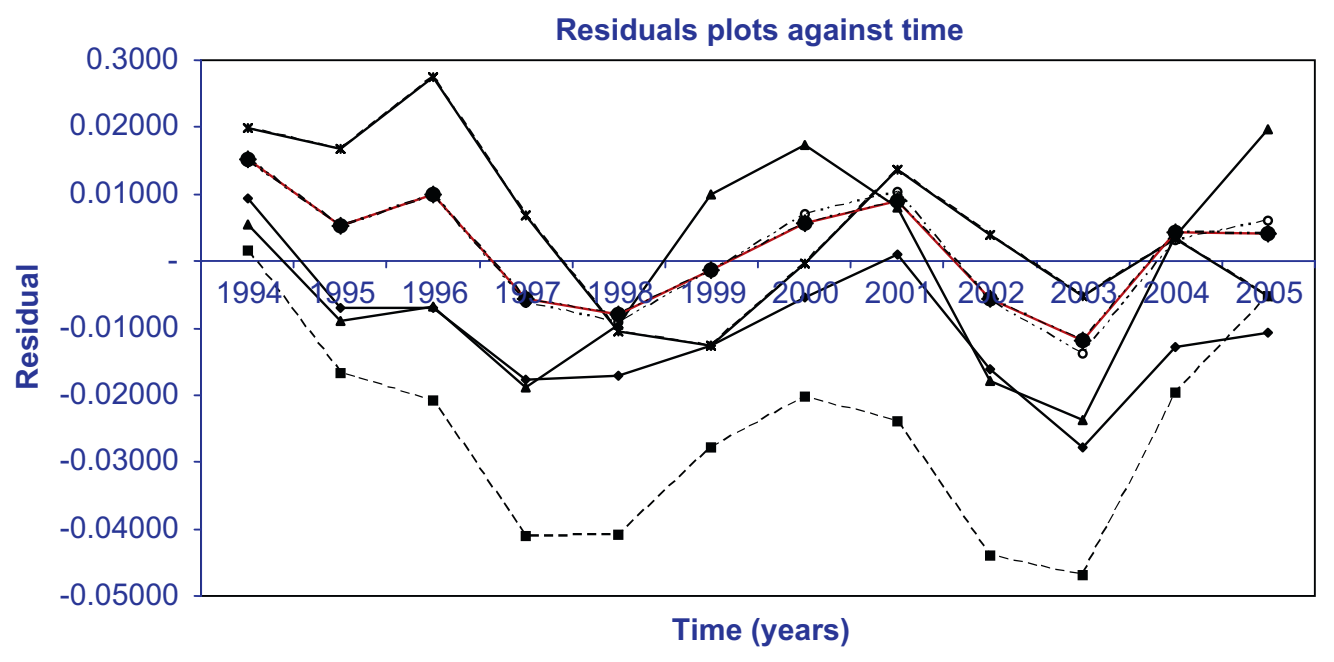

$\longrightarrow$ Bass Discrete - $\rightarrow-$ Bass General $\multimap$ Linear Logistic $\longrightarrow$ - Gompertz I

$--*-$ Gompertz II $\longrightarrow-$ Box-Cox $-\cdot+\cdot \cdot$ FLOG --o-.. Tonic

Fig. 4. Model evaluation results—residuals plots (observed value-fitted value) against time. 
estimation of these forces - extremely valuable information to decision and policy makers. The time that the adoption process is expected to be self-sustaining can be accordingly estimated, as it corresponds to the first time period in which the total number of adopters exceeds the ratio of $p$ to $q$ (Phillips, 2007). At this time, confidence in sustainability is high, because the majority of new adopters are imitators. In the case of Greece, the estimated values $(p \approx 0.001$ and $q \approx 0.63)$ indicate that the market consists mainly of imitators. This information, especially if combined with estimation results from other high-technology products, can provide useful directions for the construction of a firm's strategic plans, which are usually related to present as much as future required investments.

As far as the Gompertz models are concerned, their parameters have also been estimated using NLS. The growth process estimated by the Gompertz models fits the actual data quite adequately, in terms of statistical measures of precision. Although the model fits the initial introduction stage of the innovation less adequately, it performs well after the year 1997.

The estimates based on the logistic family models are also reported in Table 2 . The fit is quite acceptable and the calculated MAPE values are roughly of the same level. However, there is an observable divergence in the values of $S$ (saturation level) estimated by each model, although the models all report estimated values exceeding unity.

Furthermore, all the models are related to acceptable values calculated for the coefficient of multiple determination ( $R$-squared), as well as for the adjusted coefficient of multiple determination ( $R_{\mathrm{a}}$-squared). Equally acceptable are the values calculated for the rest of the statistical errors.

\section{Conclusions}

It can be concluded that existing models are quite capable of describing the diffusion process of mobile phone subscriptions. All models forecast a saturation level greater than $100 \%$, which can be easily explained by considering multiple, often personal and business subscriptions, or prepaid and postpaid ones. Moreover, as market competition increases, mobile operators propose attractive offers resulting in higher churn effects, which is an important factor in market analysis and forecasting.

The different values of estimations for the market potential or the saturation level spanning 111-126\% provide information regarding the lower and upper bounds to which the diffusion process is expected to move - clearly important intelligence for market operators.

For policy purposes, a ranking of the models, based on their data approximation precision over the particular dataset, can be extracted from the analysis.

It can be observed that the calculated statistical errors for the Bass models are quite high, indicating that the models are inappropriate for this particular dataset for accurate diffusion estimation and forecasting. The Gompertz models seem to fail in successfully estimating early years' recorded data, as they reveal high values of absolute errors. Nevertheless, they provide quite accurate estimations for the following years, as depicted in the corresponding values of take-off MAPE (TO). Moreover, the values of MAPE of the Gompertz models over the withheld period (HB) are the smallest, as compared to the MAPEs of the rest of the participating models. Logistic family models converge on the actual data quite reliably as well, having low values of calculated errors. However, since one of the main concerns includes forecasting the mobile diffusion process over the next few years, the Gompertz model is considered as the most appropriate, based on the lowest values of MAPE over the data corresponding to the withheld period (HB) as well as the data that correspond to the take-off dataset (TO). Forecasting results are presented and contrasted in Fig. 3.

From the policy point of view, the analysis of different diffusion models with respect to mobile telephony in Greece demonstrates that the saturation level of the market was already met in year 2003. Therefore, the market is now probably mature enough to welcome a new technology such as the next generations of mobile telephony. With this in mind, two operators, namely Vodafone and Wind (ex. TIM Hellas), are planning to offer HSDPA (High Speed Downlink Packet Access) services, aiming to maintain high ARPU rates and increase their market shares. Also, given the immaturity of the fixed broadband market, mobile operators plan to move towards triple- and/or quadruple-play services in order to increase their revenues and profit margins.

Although the introduction of GSM was somewhat delayed in Greece (1994) and an oligopoly market is still operating, high diffusion speeds have been achieved and saturation levels have been reached. Reasons for this 
include the influential interaction between the groups of adopters and nonadopters, as expressed by a "wordof-mouth" process (Bass, 1969), as well as the number of competitors, especially in the infancy period of mobile telephony, which is related to an intensive and persuasive marketing strategy for attracting users. Both of these assertions are adequately depicted. Indeed, during 1998, the recorded number of mobile subscribers more than doubled, as compared to the previous year's subscriptions. Although there has been a continuously incremental process in adoption since the introduction of mobile technology, the actual take-off was recorded between the years 1997 and 1998. This chronologically coincides with the entrance into the market of the incumbent fixed-line operator, OTE. On the other hand, the entry of Q-Telecom, as a fourth entrant in 2002, in a rather saturated market, highlighted the limited market potential of Greek mobile market.

From the standpoint of economics, telecommunications constitute a typical example of a network product. Consequently, a user's utility increases as the number of adopters increases too. In accordance with this concept, influential interaction among adopters and nonadopters, as realized by a word-of-mouth process, further accelerates the adoption rate. This is captured by the high calculated values of the $q$ parameters of both Bass models (at about 0.6). Moreover and in terms of competition, evidence from Greece accords with Geroski (2000) who states that "too much competition slows diffusion". Taking this observation into consideration, it can be demonstrated that the Greek market followed an interesting pathway regarding the introduction and growth of mobile telephony. The inception of market structure took the form of a duopoly quickly transforming into oligopoly. However, it has never attained the state of a fully competitive market characterized by "too much competition" and consequently "slow diffusion".

Because "diffusion is as much a process by which usage spreads and this means that there is probably not a hard and fast distinction to be drawn between technology policies designed to generate new technology and those designed to increase the usage of existing technologies" (Geroski, 2000), the forecasts presented in this paper are useful for telecom companies, regulation bodies and researchers, as they concern the introductory period of new technologies, while highlighting movements towards increasing usage of existing ones.

As has become evident, the total number of users is likely to increase over time; thus, the critical factor for the adoption of new technology (like $3 \mathrm{G}$ and $4 \mathrm{G}$ ) is the initial users, the innovators, who seem to influence the speed and the potential size of the diffusion.

It should not be ignored that a successful diffusion process depends not only on the innovation itself but also on a properly defined regulatory framework. Without doubt, the innovation itself is of major importance; however, the development of an appropriate regulatory framework should not be underestimated, as technological development by itself does not suffice for an innovation to merit a successful diffusion process. This is the main mission of national regulatory authorities, whose responsibilities include promotion of the development of new technologies, and supervision of proper operation of the relevant market, in terms of market competition and protection of the interests of the end-users.

Some aspects for further research include the examination of the diffusion patterns between prepaid and postpaid subscriptions as historical evidence reveals that users' choices often vary. Another topic of interest remains the allocation of usage between mobile phones and fixed telephony in the context of complementarity or substitutability of mobile and fixed telephony.

A final but substantially important factor, related to the diffusion process of either newly introduced innovations or existing ones, is the pricing policy adopted by the providers. Regarding the case studied, of the Greek mobile telephony market, during the last 3-4 years, prices in mobile services faced a reduction at about 54\%. Future trends and the situation in Greece are expected to be in accordance with the rest of Europe, where mobile telephony has manifested an increase in diffusion and usage, while fixed line remains constant.

\section{Appendix. Durbin-Watson statistic}

Durbin-Watson (DW) statistic is a measure of autocorrelation or serial correlation (nonrandomness) in the residuals of a least squares regression analysis. As the autocorrelation increases, the DW statistic decreases. The larger the correlation is, the less reliable the results of the regression analysis. 
The null hypothesis that there is no correlation between the successive residuals is evaluated by

$$
\mathrm{DW}=\frac{\sum_{i=2}^{n}\left(e_{i}-e_{i-1}\right)^{2}}{\sum_{i=1}^{n} e_{i}^{2}},
$$

where $e_{i}$ is the residual corresponding to the observation $i$ and $e_{i-1}$ is the residual of the preceding observation.

The value of the DW statistic ranges from 0 to 4 . A value of 2 indicates no autocorrelation, 0 indicates positive autocorrelation, and 4 indicates negative autocorrelation. As a rule of thumb, DW between 1.5 and 2.5 is inferred to indicate independence of observations.

\section{References}

Bass, F. M. (1969). A new product growth model for consumer durables. Management Science, 15(5), 215-227.

Bass, F., Krishnan, T., \& Jain, D. (1994). Why the Bass model fits without decision variables. Marketing Science, 13(3), $203-223$.

Bewley, R., \& Fiebig, D. (1988). A flexible logistic growth model with applications in telecommunications. International Journal of Forecasting, 4(2), 177-192.

Botelho, A., \& Pinto, L. C. (2004). The diffusion of cellular phones in Portugal. Telecommunications Policy, 28(5/6), $427-437$.

European Social Statistics: Demography, (2001 edition).

Fildes, R., \& Kumar, V. (2002). Telecommunications demand forecasting - a review. International Journal of Forecasting, 18(4), 489-522.

Fisher, J. C., \& Pry, R. H. (1971). A simple substitution model of technological change. Technology Forecasting and Social Change, 3(1), 75-88.

Geroski, P. A. (2000). Models of technology diffusion. Research Policy, 29(4/5), 603-625.

Gompertz, B. (1825). On the nature of the function expressive of the law of human mortality, and on a new mode of determining the value of life contingencies. Philosophical Transactions of the Royal Society of London, 115, 513-585.

Gruber, H. (2005). The economics of mobile telecommunications. New York: Cambridge University Press.

Heeler, R., \& Hustad, T. (1980). Problems in predicting new product growth for consumer durables. Management Science, 26(10), $1007-1020$.

Mahajan, V., Muller, E., \& Bass, F. M. (1990). New product diffusion models in marketing: A review and directions for research. Journal of Marketing, 54(1), 1-26.

Mahajan, V., Muller, E., \& Srivastava, R. (1990). Determination of adopter categories using innovation diffusion models. Journal of Marketing Research, 27(2), 37-50.

National Statistical Service of Greece. (2005). Greece in figures. Available from $<$ http://www.statistics.gr/eng_tables/hellas_in_numbers_ eng.pdf $>$.

Phillips, F. (2007). On S-curves and tipping points. Technological Forecasting \& Social Change, 74, 715-730.

Rai, L. P. (1999). Appropriate models for technology substitution. Journal of Scientific \& Industrial Research, 58(1), 14-18.

TONIC. 2000. EU IST-2000-25172 TONIC project. Deliverables and related publications available from 〈http://www.nrc.nokia.com/ tonic/ $>$.

Wright, M., Upritchard, C., \& Lewis, T. (1997). A validation of the Bass new product diffusion model in New Zealand. Marketing Bulletin, 8(2), 15-29. 